\title{
Prostate cancer: an emerging threat to the health of aging men in Asia
}

\author{
Ling Zhang ${ }^{1}$, Bao-Xue Yang ${ }^{1}$, Hai-Tao Zhang ${ }^{2}$, Jin-Guo Wang ${ }^{1,3}$, Hong-Liang Wang ${ }^{1,3}$ and Xue-Jian Zhao ${ }^{1,3}$
}

The aim of this study was to determine and examine the possible reasons for the difference in prostate cancer incidence between Asian men and North American men by literature review. Data regarding cancer incidence and mortality were obtained from the database of the International Agency for Research on Cancer (IARC). A literature review was conducted by studying related articles published in peer-reviewed journals such as the The New England Journal of Medicine, Journal of Clinical Oncology, A Cancer Journal for Clinicians and Asian Journal of Andrology. To evaluate the early diagnosis and survival rates, the mortality-to-incidence rate ratio (MR/IR) was calculated from the IARC data. By comparing prostate cancer data between Asian men and North American men, we found that differences in the incidence rate and MR/IR could be attributed largely to a lack of annual prostate cancer screening with serum prostate-specific antigen (PSA) in most Asian countries. It is likely that PSA screening also contributes significantly to the differences in prostate cancer mortality rates. Prostate cancer has the highest incidence rate among five common malignancies in Asian Americans. However, the MR/IR ratio of prostate cancer is the lowest among cancers. These data seem to further support the usefulness of PSA screening, even though the percentage of low risk cancers is greater in prostate cancer than in other cancers. The low incidence rate of prostate cancer does not reflect the actual statistics of this disease in Asia. The data from limited institutions in many Asian countries seem to bias the true incidence and mortality rates. To improve this situation, incorporating PSA screening for prostate cancer, as well as constructing a nationwide cancer registration system, will be helpful.

Asian Journal of Andrology (2011) 13, 574-578; doi:10.1038/aja.2010.126; published online 9 May 2011

Keywords: Incidence; mortality; prostate cancer; prostate-specific antigen

\section{INTRODUCTION}

The trend of an aging population presents a serious socioeconomic problem in Asian countries. The population over 60 years old in Asia is about four times greater compared to those of North America and Europe. ${ }^{1}$ Thus, health problems will be a greater burden in Asian countries despite rapid socioeconomic growth. Cancer is commonly associated with aging, and early diagnosis is the only way to improve treatment results and lower cancer mortality. For example, the 5-year survival rate of patients with prostate cancer when diagnosed and treated in the early stages is nearly $99 \% .^{2}$

Prostate cancer is diagnosed mostly in men above 50 years of age. However, the incidence and mortality rates of prostate cancer are very low in Asian men, and so it has not been considered a major threat in this population. According to the 2002 data from the International Agency for Research on Cancer (IARC), the United States had the highest prostate cancer incidence rate in the world at $124.8 / 10^{5}$ person year (PY).

The incidence rate of prostate cancer in China was $1.6 / 10^{5} \mathrm{PY}$, which ranked 170th. Other countries in Asia, including Japan (12.6/ $10^{5} \mathrm{PY}, 114$ th $)$, Korea $\left(7.6 / 10^{5} \mathrm{PY}, 134 \mathrm{th}\right)$ and Vietnam $\left(2.8 / 10^{5} \mathrm{PY}\right.$, $161 \mathrm{st})$, were also reported as having low incidence rates. ${ }^{3}$ Such a large difference in the prostate cancer incidence rate between North America and Asia cannot be entirely explained by variations in diet, race and environmental factors, ${ }^{4,5}$ and this fact is a cause of concern for many researchers.

\section{THE DIFFERENCE IN PROSTATE CANCER INCIDENCE RATES BETWEEN NORTH AMERICAN AND ASIAN MEN COULD BE DUE TO A DIFFERENCE IN PROSTATE-SPECIFIC ANTIGEN (PSA) SCREENING PREVALENCE}

In 2006, Kamangar et al. ${ }^{6}$ described the overall cancer incidence, mortality and prevalence of lung, breast, colon and rectum, stomach, prostate, liver, cervix and oesophageal cancer in selected geographic regions of the world using GLOBOCAN (2002) and five-continent databases from the IARC. The incidence rate of prostate cancer in North America $\left(119.9 / 10^{5} \mathrm{PY}\right)$ was nearly 25.5 times higher than that of Asia $\left(4.7 / 10^{5} \mathrm{PY}\right)$. However, the mortality rate of prostate cancer in North America was only 5.9 times higher than that in Asia $\left(15.8 / 10^{5}\right.$ PY versus $2.7 / 10^{5} \mathrm{PY}$ ). The authors stated that the enormous difference between the two continents could not be explained by variations in diet and race, and they concluded that annual screening for prostate cancer with a serum PSA measurement in men of 50 years or older in North America is likely another significant contributing factor. The authors used the mortality-to-incidence rate ratio (MR/IR) as an indirect index for the evaluation of survival and early diagnosis. The MR/IR ratio was 0.13 in North America. This means that that there

${ }^{1}$ Prostate Diseases Prevention and Treatment Research Centre, Jilin University, Changchun 130021, China, ${ }^{2}$ Department of Pathology and Laboratory Medicine, Tulane University School of Medicine, New Orleans, LA 70131, USA and ${ }^{3}$ Department of Andrology, First Hospital of Jilin University, Changchun 130021 , China Correspondence: Professor HL Wang (whl1228@126.com)

Received: 7 September 2010; Revised: 22 December 2010; Accepted: 4 January 2011; Published online: 9 May 2011 
were 13 deaths for every 100 newly diagnosed prostate cancer patients. The MR/IR in Asia was 0.57. The small value for MR/IR in North America may provide further supporting evidence that vigorous annual screening with PSA is feasible and may reduce prostate cancer mortality.

The worldwide prostate cancer MR/IR ratios from IARC decreased markedly from 2002 to $2008 .^{3,7}$ As shown in Table 1 and Figure 1, new prostate cancer cases worldwide have increased from 679060 to 914 000 during this period. Prostate cancer incidence rate has increased from $25.3 / 10^{5}$ to $28.5 / 10^{5} \mathrm{PY}$, while mortality rate has decreased from $8.2 / 10^{5}$ to $7.5 / 10^{5} \mathrm{PY}$. The MR/IR ratio has decreased from 0.32 to 0.26 . The prostate cancer incidence rate in North America has decreased from $119.9 / 10^{5}$ to $85.7 / 10^{5} \mathrm{PY}$, and the mortality rate has decreased from $15.8 / 10^{5}$ to $9.9 / 10^{5} \mathrm{PY}$, accompanied with a decrease in the MR/IR ratio from 0.13 to 0.12 . Of all the continents, Europe had the most remarkable change. The prostate cancer incidence rate increased from $40.0 / 10^{5}$ PY in 2002 to $61.4 / 10^{5}$ PY in 2008 . However, the mortality rate decreased from $14.2 / 10^{5}$ to $12.1 / 10^{5} \mathrm{PY}$ and the MR/IR ratio decreased from 0.36 to 0.20 . This remarkable progress could be attributed to the European Randomized Study of Screening for Prostate Cancer. ${ }^{8}$ Although Asia and Africa have made some improvements in mortality rates and MR/IR ratios, the changes are modest compared to other continents.

\section{REASONS FOR THE LOW INCIDENCE AND HIGH MR/IR RATIO OF PROSTATE CANCER IN ASIA}

As showed in Table 1, the prostate cancer incidence rate in Asia was $7.2 / 10^{5} \mathrm{PY}$, and the mortality rate was $3.2 / 10^{5} \mathrm{PY}$, which were markedly lower than that of other continents. The MR/IR ratio (0.44) was significantly higher than that of other continents, except for Africa. These results indicate that prostate cancer in Asia may be very small in number, but it is a very high risk disease when compared with that in other continents. However, do these results reflect reality?

Age-standardized incidence rates, mortality rates and MR/IR ratios in Asia

The data in Table 2 come from the IARC databases. ${ }^{7}$ The MR/IR ratios in Japan, Korea and Singapore had decreased to 0.22, 0.18 and 0.20, respectively, which were very close to those in Europe $(0.20)$ and North America (0.12). In Japan, the early diagnosis of prostate cancer started a relatively long time ago, and Japanese urologists pay attention to and take an active part in the early diagnosis and treatment of prostate cancer. ${ }^{9}$ In 2008 , the incidence rate of prostate cancer in China was $4.3 / 10^{5} \mathrm{PY}$, much higher than that in $2002\left(1.6 / 10^{5} \mathrm{PY}\right)$. Meanwhile, the mortality rate decreased from 0.62 to 0.42 . These results demonstrate that prostate cancer can be detected at an early stage and that treatment can be effectively performed. ${ }^{10}$ However, it should be noted here that the incidence and mortality rate data mostly came from limited clinical institutes and not from mass screening results. In Philippines, Vietnam and Malaysia, the MR/IR ratios were over 0.50. It may be shown in these countries that prostate cancer is only diagnosed at late clinical stages. In a late cancer stage, life expectancy and quality of life are considered poor.

\section{The incidence rates of prostate cancer among Asian Americans are} not low

In 2007, McCracken et al. ${ }^{11}$ compared prostate cancer incidence and mortality rates for ethnic groups of Asian Americans with those of non-Hispanic whites. The data were provided by the Los Angeles Cancer Surveillance Program and the California Cancer Registry from 2000 to 2002. The incidence rate among non-Hispanic whites was $159.9 / 10^{5}$ PY. Among all Asian ethnic groups, Filipino Americans had the highest incidence rates $\left(113.3 / 10^{5} \mathrm{PY}\right)$. The incidence rates of Japanese Americans, Chinese Americans and Vietnamese Americans were $103.4 / 10^{5}, 80.4 / 10^{5}$ and $65.4 / 10^{5} \mathrm{PY}$, respectively. Korean Americans had the lowest incidence rate (51.0/10 $\mathrm{PY}$ ). There were obviously some differences between Asian Americans and non-Hispanic whites, which might truly be associated with variations in race and lifestyle, particularly dietary differences. ${ }^{12,13}$ Furthermore, the incidence rates among Asian Americans were significantly higher than the average level $\left(4.7 / 10^{5} \mathrm{PY}\right)$ in Asian men living in their homeland. ${ }^{11}$ The MR/IR ratio is probably the most valuable indicator of cancer survival and an early diagnosis. As stated previously, the prostate cancer incidence rate $\left(51.0-113.3 / 10^{5} \mathrm{PY}\right)$ varied significantly among the Asian American ethnic groups; however, MR/IR ratios (0.111-0.146) were lower than that of nonHispanic white men (0.169). These results indicate that the incidence and mortality rates of Asian people are expected to be greatly improved, even in their homeland, by increasing PSA screening.

\section{The comparison of incidence rates and MR/IR ratios of five} malignant tumours among Asian Americans

McCracken et al. ${ }^{11}$ calculated MR/IR ratios based on the incidence and mortality rate data of five malignant tumours (Table 3). Despite the fact that prostate cancer was the most commonly diagnosed cancer among Asian American men, except for Korean and Vietnamese Americans, the MR/IR ratios of prostate cancer were significantly lower than those of lung, liver, stomach and colon/rectal cancers. All five malignant tumours could be detected by mass screening, but why were the MR/IR ratios of prostate cancer lower than that of the other four cancers? PSA is secreted by the prostate gland epithelial cell and is a tissue-specific antigen of the prostate. Adenocarcinoma cells have the ability to secrete PSA into interstitial fluid and elevate the serum PSA level. Because the prostate gland is of parenchymatous organ, prostate cancer can be diagnosed easily and safely by ultrasoundguided systematic biopsy. PSA mass screenings annually performed in North America have increased patient diagnoses at early stages and facilitated efficient treatment. One study has demonstrated that

Table 1 Worldwide age-standardized incidence rates, mortality rates and mortality-to-incidence rate ratios $(2008)^{7}$

\begin{tabular}{|c|c|c|c|c|c|}
\hline & Cases & Incidence rate (cases $/ 10^{5} \mathrm{PY}$ ) & Death & Mortality rate (cases $/ 10^{5} \mathrm{PY}$ ) & $M R / I R$ ratio \\
\hline World & 913770 & 28.5 & 258381 & 7.5 & 0.26 \\
\hline North America & 213705 & 85.7 & 32591 & 9.9 & 0.12 \\
\hline Oceania & 21428 & 94.5 & 4294 & 15.3 & 0.16 \\
\hline Europe & 385440 & 61.4 & 89908 & 12.1 & 0.20 \\
\hline South America & 84111 & 50.2 & 29274 & 16.2 & 0.32 \\
\hline Asia & 133171 & 7.2 & 59643 & 3.2 & 0.44 \\
\hline Africa & 39460 & 17.5 & 28006 & 12.5 & 0.71 \\
\hline
\end{tabular}

Abbreviation: MR/IR, mortality-to-incidence rate ratio. 


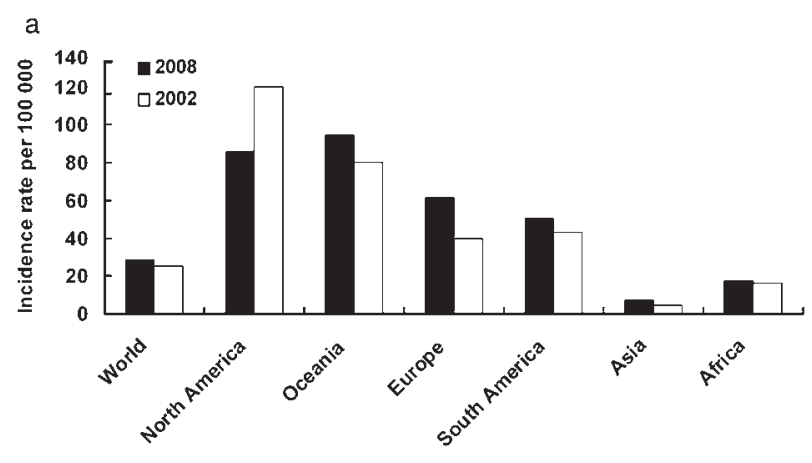

Systematic multiple biopsies, as performed in the prostate, are usually not suitable for a secondary examination. In addition, prostate cancer is generally slow growing in nature compared to other cancers, especially low-risk cancers with a PSA $<10 \mathrm{ng} \mathrm{ml}^{-1}$ and a Gleason score $<7$, which seems to the reason that the four other cancers are diagnosed at a later clinical stage compared to prostate cancer.

\section{PREVALENCE OF PSA SCREENING IN MEN OVER 50 YEARS OLD IS IMPERATIVE IN ASIAN COUNTRIES}

The analysis of prostate cancer incidence rates and the MR/IR ratios suggests that the incidence rates were not in fact low in the Asian population. The fact that MR/IR ratios were significantly lower in Asian Americans than in white Americans suggests that the prevalence of PSA screening will make it possible to detect prostate cancer at early stages and treat the disease efficiently in Asian countries. In addition, our group has conducted a PSA-based prostate cancer screening in men over 50 years old in Changchun, China. The results showed that the overall prostate cancer detection rate in this cohort was $1.7 \%$. However, cases with Gleason scores 8-10 accounted for 34\% of all prostate cancer cases. ${ }^{10,14-16}$ Our data suggest that the prostate cancer incidence rate in China would be almost equivalent to those of Europe and the United States; prostate cancer is prevalent in developing Asian countries and the mortality risk can no longer be ignored. Furthermore, the data suggest that the rate of high-risk patients may be variable and dependent on lifestyle and/or ethnic background from country to country.

Prostate cancers with Gleason scores $\leqslant 6$ are classified as welldifferentiated cancers. This kind of prostate cancer has the lowest invasive potential, often forms a carcinoma nodus and develops slowly. When the carcinoma nodus grows into the urethra, it will result in difficult urination, which forces the patient to the hospital. However, if difficult urination is due to the cancer, it is likely at an advanced stage and the best opportunity for treatment may have been lost. These are the prostate cancer patients that urologists can usually detect in the clinic. Some urologists in China look at prostate cancer as a very slow-growing cancer that is not life threatening in nature. These traditional views sometimes result in mismanagement and allow the cancer to metastasize.

Prostate cancers with Gleason scores $\geqslant 8$ have highly invasive abilities, and micrometastases are often present even at an early stage. ${ }^{17}$ Prostate cancer cells of this type will demonstrate the ability for infiltrative growth into the interstitial space instead of forming a carcinoma nodus that often oppresses the urethra. In such cases, patients will not have any genitourinary symptoms leading them to visit an urologist even in advanced stages until metastases symptoms develop. An early stage cancer generally shows no symptoms; therefore, in order to detect the cancer early, a mass screening system is important. Measurement of the serum PSA has been recognized worldwide as a safe and cost-effective method for detecting prostate cancer, and it is graphy, magnetic resonance imaging or endoscopic examination.

the 5-year survival rate of clinically localized prostate cancer reaches $99 \% .^{2}$ Although lung, liver, stomach and colon/rectum cancers have their respective markers, they are generally useful only at advanced clinical stages. These cancers can be diagnosed mainly by imaging

Table 2 Age-standardized incidence rates, mortality rates and mortality-to-incidence rate ratios in Asia (2008) ${ }^{7}$

\begin{tabular}{|c|c|c|c|c|c|}
\hline & Cases & Incidence rate (cases $/ 10^{5} \mathrm{PY}$ ) & Death & Mortality rate (cases $/ 10^{5} \mathrm{PY}$ ) & $M R / I R$ ratio \\
\hline China & 33802 & 4.3 & 14297 & 1.8 & 0.42 \\
\hline Japan & 38619 & 22.7 & 9989 & 5.0 & 0.22 \\
\hline Korea & 6382 & 22.4 & 1204 & 4.1 & 0.18 \\
\hline Singapore & 616 & 20.0 & 125 & 3.9 & 0.20 \\
\hline Philippines & 2491 & 10.1 & 1290 & 5.3 & 0.52 \\
\hline Vietnam & 1208 & 3.2 & 716 & 1.9 & 0.59 \\
\hline Malaysia & 821 & 9.2 & 508 & 5.8 & 0.63 \\
\hline
\end{tabular}

Abbreviation: MR/IR, mortality-to-incidence rate ratio. 
Table 3 The comparison of age-adjusted incidence rates, mortality rates and mortality-to-incidence ratios for five kinds of cancers between Asia Americans and white Americans (per 100 000) $)^{11}$

\begin{tabular}{|c|c|c|c|c|c|c|c|}
\hline & & Chinese & Filipino & Vietnamese & Korean & Japanese & Non-Hispanic white \\
\hline \multirow[t]{3}{*}{ Prostate cancer } & IR & 80.4 & 113.3 & 65.4 & 51.0 & 103.4 & 159.9 \\
\hline & MR & 8.9 & 15.7 & 9.1 & 7.1 & 15.1 & 27.0 \\
\hline & MR/IR & 0.11 & 0.14 & 0.14 & 0.15 & 0.14 & 0.17 \\
\hline \multirow[t]{3}{*}{ Lung cancer } & IR & 52.3 & 71.9 & 72.8 & 56.3 & 41.1 & 77.9 \\
\hline & MR & 46.6 & 49.8 & 47.2 & 52.3 & 36.0 & 64.0 \\
\hline & MR/IR & 0.89 & 0.69 & 0.65 & 0.93 & 0.88 & 0.82 \\
\hline \multirow[t]{3}{*}{ Colon/rectum cancer } & IR & 52.2 & 48.4 & 39.1 & 57.8 & 57.8 & 57.8 \\
\hline & MR & 18.2 & 16.6 & 11.1 & 19.1 & 27.1 & 21.3 \\
\hline & $\mathrm{MR} / \mathrm{IR}$ & 0.35 & 0.34 & 0.28 & 0.34 & 0.42 & 0.36 \\
\hline \multirow[t]{3}{*}{ Stomach cancer } & $\mathrm{IR}$ & 18.3 & 7.2 & 28.1 & 54.6 & 27.0 & 9.5 \\
\hline & MR & 14.1 & 4.1 & 15.5 & 35.2 & 18.1 & 5.0 \\
\hline & $\mathrm{MR} / \mathrm{IR}$ & 0.77 & 0.57 & 0.55 & 0.65 & 0.67 & 0.53 \\
\hline \multirow[t]{3}{*}{ Liver cancer } & IR & 23.3 & 16.8 & 54.3 & 33.7 & 9.3 & 6.8 \\
\hline & MR & 19.9 & 12.0 & 35.5 & 26.6 & 8.3 & 6.0 \\
\hline & MR/IR & 0.85 & 0.71 & 0.65 & 0.79 & 0.89 & 0.88 \\
\hline
\end{tabular}

the only effective method to detect prostate cancer at an early stage. The percentage of prostate cancers with a Gleason score $\geqslant 8$ was $34 \%$ according to data from the PSA mass screening in Changchun, China. ${ }^{16}$ Stamey et al. ${ }^{18}$ also showed that the percentages of tumours with a Gleason score $\geqslant 8$ during four successive 5 -year periods were $30.89 \%, 26.82 \%, 28.00 \%$ and $35.03 \%$, respectively, from 1983 to 1988 . These results indicate that PSA screening can result in the early diagnosis and treatment of prostate cancer as well as the detection of early stage cancer, but cannot change the pathological grade. PSA mass screening can diagnose cancer irrespective of its malignancy; highly malignant prostate cancer can also be detected at its early stage without metastasis allowing for curative treatment. For this reason, both the incidence rates and the MR/IR ratios significantly decreased in 2008 compared with those in 2002 in the IARC data.,

On the other hand, PSA screening would lead to an overdiagnosis and overtreatment for tumours with a Gleason score $\leqslant 6 .{ }^{19,20}$ The American Cancer Society pays great attention to the issue of overdiagnosis and overtreatment and emphasizes providing sufficient information about screening to allow participants to make an informed decision. The American Cancer Society recommends that men should begin to receive PSA screenings at age 50. Men at higher risk should receive screening from the age of 45 . For men whose PSA is $<2.5 \mathrm{ng} \mathrm{ml}^{-1}$, screening intervals can be extended to every 2 years. With a PSA level between 2.5 and $4.0 \mathrm{ng} \mathrm{ml}^{-1}$, screening should be conducted annually. Men with a PSA level $\geqslant 4.0 \mathrm{ng} \mathrm{ml}^{-1}$ are recommended to be referred for further evaluation or a prostate biopsy. ${ }^{21}$

The effect of prostate cancer screening on prostate cancer mortality was observed in two similar studies with different results. The United States-based Prostate, Lung, Colorectal, and Ovarian Cancer Screening Trial indicated that the death rate from prostate cancer was very low and did not differ significantly between a PSA screening group and a control group. ${ }^{22}$ However, Hugosson et al. ${ }^{23}$ found that PSA-based population screening for prostate cancer led to a $44 \%$ reduction in prostate cancer disease-specific mortality. Higher contamination with opportunistic screening of the control group was thought to be the reason for the contradicting results of the US study. PSA screening rates in Asian developing countries are still very low, and even in Japan, the percentage of men over 50 years of age who received PSA screenings was estimated to be less than $20 \% .{ }^{24}$ Men had little opportunity to take part in a screening in most Asian countries if they were not invited. Similar trials are needed to evaluate the effects of PSA screening on prostate cancer mortality in Asia.

\section{SUMMARY}

In this review, we have examined the possible reasons for the difference in prostate cancer incidence rates and MR/IR ratios between Asia and North America. Annual screening for prostate cancer with PSA in aging men in North America leads to early detection and treatment at as early a stage as possible. A nationwide cancer screening system results in the detection of numerous cancer patients at an early stage and leads to a higher prostate cancer incidence rate and lower MR/IR ratio. The higher prostate cancer incidence rates among Asian American men suggest that the incidence rate in native Asian men would be much higher if they received annual PSA screening. The low MR/IR ratio in Asian American men is equivalent to that of NonHispanic whites and is the lowest of five kinds of malignant tumours, suggesting that PSA screening has the potential to improve prostate cancer mortality and increase the cancer detection rate because the tumour marker has a high specificity. Therefore, PSA mass screening should be promoted more vigorously in Asian countries.

\section{COMPETING FINANCIAL INTERESTS}

The authors declare no competing financial interests.

\section{ACKNOWLEDGMENTS}

The authors are grateful to Professor Masaaki Kuwahara for his critical reading and revising of our manuscript. This work was funded by the National Natural Science Foundation of China (Nos. 30801354 and 30970791) and Jilin Provincial Science \& Technology Department China (No. 20080154).

1 Extermann M. Geriatric oncology: an overview of progresses and challenges. Cancer Res Treat 2010; 42: 61-8.

2 Ries LA, Melbert D, Krapcho M, Stinchcomb DG, Howlader N et al. SEER Cancer Statistics Review, 1975-2005. Bethesda, , MD: National Cancer Institute. http:// seer.cancer.gov/csr/1975_2005/, based on November 2007 SEER data submission, posted to the SEER website, 2008.

3 Ferlay J, Bray F, Pisani P, Parkin DM. GLOBOCAN 2002: Cancer Incidence, Mortality and Prevalence Worldwide. IARC Cancer-Base No. 5, version 2.0. Lyon: IARC Press; 2004.

4 Mao X, Yu Y, Boyd LK, Ren G, Lin D et al. Distinct genomic alterations in prostate cancers in Chinese and Western populations suggest alternative pathways of prostate carcinogenesis. Cancer Res 2010; 70: 5207-12.

5 Venkateswaran V, Klotz LH. Diet and prostate cancer: mechanisms of action and implications for chemoprevention. Nat Rev Urol 2010; 7: 442-53.

6 Kamangar F, Dores GM, Anderson WF. Patterns of cancer incidence, mortality, and prevalence across five continents: defining priorities to reduce cancer disparities in different geographic regions of the world. J Clin Oncol 2006; 24: 2137-50. 
neg

Prostate cancer: an emerging threat in Asia

L Chang et al

578

7 Ferlay J, Shin HR, Bray F, Forman D, Mather C et al. Estimates of worldwide burden of cancer in 2008: GLOBOCAN 2008. Int J Cancer 2010; 127: 2893-917.

8 Schröder FH, Hugosson J, Roobol MJ, Pamela TL, Ciatto S et al. Screening and prostate-cancer mortality in a randomized European study. N Eng J Med 2009; 360: 1320-8.

9 Ishidoya S, Ito A, Orikasa K, Kawamura S, Tochigi T et al. The outcome of prostate cancer screening in a normal Japanese population with PSA of 2-4 $\mathrm{ng} / \mathrm{ml}$ and the free/ total PSA under 12\%. Jpn J Olin Oncol 2008; 38: 844-8.

10 Zhang L, Wu S, quo LR, Zhao XJ. Diagnostic strategies and the incidence of prostate cancer: reasons for the low reported incidence of prostate cancer in China. Asian J Androl 2009; 11: 9-13.

11 McCracken M, Olsen M, Chen MS Jr, Jemal A, Thun M et al. Cancer incidence, mortality, and associated risk factors among Asian Americans of Chinese, Filipino, Vietnamese, Korean, and Japanese ethnicities. CA Cancer J Chin 2007; 57: 190-205.

12 Marks LS, Kojima M, Demarzo A, Heder D, Bostwick DG et al. Prostate cancer in native Japanese and Japanese-American men: effects of dietary differences on prostatic tissue. Urology 2004; 64: 765-71.

13 Whittemore AS, Kolonel LN, Wu AH, John EM, Gallagher RP et al. Prostate cancer in relation to diet, physical activity, and body size in blacks, whites, and Asians in the United States and Canada. J Nat/ Cancer Inst 1995; 87: 652-61.

14 Li X, Tsuji I, Kuwahara M, Chang H, Wang $\mathrm{H}$ et al. Mass screening of prostate cancer in Changchun City of China. Int Urol Nephrol 2004; 36: 541-8.

15 Zhang HF, Wang HL, Xu N, Li SW, Ii GY et al. Mass screening of 12027 elderly men for prostate carcinoma by measuring serum prostate specific antigen. Chin Med J (Engl) 2004; 117: 67-70.
16 Gao HW, Li YL, Wu S, Wang YS, Chang HF et al. Mass screening of prostate cancer in a Chinese population: the relationship between pathological features of prostate cancer and serum prostate specific antigen. Asian J Androl 2005; 7: 159-63.

$17 \mathrm{Li} \mathrm{Y,} \mathrm{Mao} \mathrm{JH,} \mathrm{Zhang} \mathrm{L,} \mathrm{Ji} \mathrm{GY,} \mathrm{Pan} \mathrm{YZ} \mathrm{et} \mathrm{al.} \mathrm{Study} \mathrm{on} \mathrm{relationship} \mathrm{between} \mathrm{the}$ expression of PSA ERNA and protein in the mononuclear cells of the peripheral blood and prostate cancer micrometastasis. Chin J Androl 2006; 20: 5-7.

18 Stamey TA, Caldwell M, Mc Neal JE, Volley R, Hemenez M et al. The prostate specific antigen era in the United States is over for prostate cancer: what happened in the last 20 years? J Urol 2004; 172: 1297-301.

19 Ross LE, Berkowitz Z, Ekwueme DU. Use of the prostate specific antigen test among U.S. men: findings from the 2005 National Health Interview Survey. Cancer Epidemiol Biomarkers Prev 2008; 17: 636-44.

20 Barry MJ, Mulley AJ Jr. Why are a high overdiagnosis probability and a long lead time for prostate cancer screening so important? J Natl Cancer Inst 2009; 101: 374-83.

21 Smith RA, Cokkinides V, Brooks D, Sallow D, Brawley OW. Cancer Screening in the United States, 2010: a review of current American Cancer Society guidelines and issues in cancer screening. CA Cancer J Chin 2010; 60: 99-119.

22 Andriole GL, Crawford ED, Grubb RL 3rd, Buys SS, Cha D et al. Mortality results from a randomized prostate-cancer screening trial. N Eng J Med 2009; 360: 1310-9.

23 Hugosson J, Carlsson S, Aus G, Bergdahl S, Khatami A et al. Mortality results from the Goteborg randomised population-based prostate-cancer screening trial. Lancet Oncol 2010; 11: 725-32.

24 Namiki M, Akaza H, Lee SE, Song JM, Umbas R et al. Prostate Cancer Working Group Report. Jpn J Olin Oncol 2010; 40 (Suppl 1): i70-5.

Asian Journal of Andrology 